\title{
2019: Recommendations for Reducing Tobacco Consumption in Portuguese-Speaking Countries - Positioning of the Federation of Portuguese Language Cardiology Societies
}

\author{
Gláucia Maria Moraes de Oliveira, ${ }^{10}$ Miguel Mendes, ${ }^{2}$ Oscar Pereira Dutra, ${ }^{3}$ Aloysio Achutti, ${ }^{4}$ Mario Fernandes, ${ }^{5}$ \\ Vanda Azevedo, ${ }^{6}$ Maria Beatriz Sena e Costa Santos Ferreira, ${ }^{7}$ Armando Serra Coelho, ${ }^{8}$ Miryan Bandeira dos \\ Prazeres Cassandra Soares, ${ }^{9}$ Mário Alberto Brito Lima Évora, ${ }^{10}$ Mário Gomes Mariotto, ${ }^{11}$ João Araujo Morais ${ }^{12}$ \\ Universidade Federal do Rio de Janeiro, ${ }^{1}$ Rio de Janeiro, $R J-$ Brazil \\ CHLO - Hospital de Santa Cruz, ${ }^{2}$ Carnaxide - Portugal \\ Instituto de Cardiologia, ${ }^{3}$ Porto Alegre, RS - Brazil \\ Universidade Federal do Rio Grande do Sul, ${ }^{4}$ Porto Alegre, RS - Brazil \\ Universidade de Luanda, ${ }^{5}$ Luanda - Angola \\ Colégio de Especialidade de Cardiologia, ${ }^{6}$ Praia - Cabo Verde \\ Instituto do Coração ICOR, ${ }^{7}$ Maputo - Moçambique \\ Clínica Santos Dumont, ${ }^{8}$ Lisboa - Portugal \\ Hospital Dr. Ayres de Menezes, ${ }^{9}$ São Tomé - São Tomé e Príncipe \\ Hospital do Governo de Macau, ${ }^{10}$ Região Administrativa Especial de Macau - Macau \\ Hospital Nacional Simão Mendes, ${ }^{11}$ Bissau - Guiné-Bissau \\ Centro Hospitalar de Leiria, ${ }^{12}$ Leiria - Portugal
}

\section{Introduction}

Depending on the epidemiological perspective of the observer and the extent of his concept of causality, tobacco consumption can be considered the second cause in the world of death attributed to classic cardiovascular risk factors, preceded only by hypertension, and the first cause of premature death and disabilities. When understood as an immediate cause without contextualization in the complex that determines and maintains population behavior, smoking was responsible in the world for about 8.10 (7.79-8.41) million deaths and 213.39 (201.16-226.66) million healthy life years lost (disability-adjusted life-years, DALYs). Although the number of daily smokers (individuals aged 15 years and older who smoke daily) has decreased, the total number of smokers continues to increase, imposing a major global challenge for healthcare systems. ${ }^{1}$

Physicians, who generally deal directly and individually with the patient, tend to consider health/illness limited to the patient's organic commitment and personal history and are less appreciative of the "causes of the causes" and the psychosocial determinants of the phenomena and behaviors, inseparable from the ecological context and interests. Environmental pollution (which has also a contribution from smoking and is progressively increasing) is currently considered to be the most important cause of morbidity and mortality

\section{Keywords}

Tobacco Use Disorder/epidemiology; Tobacco Use Disorder/ mortality; Smoking Prevention; Socioeconomic Factors; Urban Population; Rural Population; Tobacco Smoke Pollution.

Mailing Address: Gláucia Maria Moraes de Oliveira •

Universidade Federal do Rio de Janeiro - R. Prof. Rodolpho P. Rocco, 255 - $8^{\circ}$ Andar - Sala 6, UFRJ. Postal Code 21941-913, Cidade Universitária, RJ - Brazil E-mail: glauciam@cardiol.br, glauciamoraesoliveira@gmail.com

DOI: 10.5935/abc.20190071 in the world's population, ${ }^{2}$ extending the spectrum beyond the traditionally valued risk factors. This perspective is very important for an understanding of the resistance to smoking control and planning of strategies that are more effective to approach this issue.

In all Portuguese-speaking countries (PSCs), smoking is more frequent among men; the difference in rates between men and women vary among the countries and are greater in the African countries. Table 1 describes the standardized prevalence by sex in 2015 and the annualized difference for men and women from 1990 to 2015 according to the sociodemographic index (SDI). ${ }^{3}$ The rates of daily smokers vary from $19.0 \%, 16.8 \%$, and $7.2 \%$, in African countries, Portugal, and Brazil, respectively. ${ }^{4}$

Available data from the National Health Surveys (NIH) (1987, 1995/96, 1998/99, 2005/06, and 2014) showed that daily consumption of tobacco in Mainland Portugal decreased among men by $35.2 \%$ (95\% confidence interval [Cl] $34.2-36.2 \%$ ) in 1987 to $26.7 \%$ (95\% Cl 25.2-28.3\%) in 2014 , and progressively increased in women from $6.0 \%(95 \%$ Cl 5.6-6.4\%) in 1987 to $14.6 \%$ (95\% Cl 13.6-15.8\%) in 2014, with a higher daily consumption in men of more disadvantaged socioeconomic groups and the opposite in women. ${ }^{5}$

The described prevalence of tobacco consumption in Mozambique in 2003 was $39.9 \%$ in men and $18.0 \%$ in women. ${ }^{6}$ In a 2005 sample from the same country, the prevalence of daily smokers (including users of chewing tobacco, snuff, manufactured cigarettes, and hand-rolled cigarettes) reduced to $33.6 \%$ in men and $7.4 \%$ in women, with different prevalence rates by sex and country regions.'

Brazil is the leading country in the control of smoking, with the third largest decline in prevalence of daily smokers since 1990: $57 \%$ and $56 \%$ for men and women, respectively. This was achieved with a robust public policy, in which advertisements about health damage caused by the tobacco were associated with restrictions on consumption and tax increases for such products, among other measures. ${ }^{8}$ 
Table 1 - Standardized prevalences by sex in 2015, and annualized difference by sex from 1990 to 2015 according to the sociodemographic index

\begin{tabular}{|c|c|c|c|c|c|}
\hline & SDI Level & $\begin{array}{c}\text { Women Standardized } \\
\text { Prevalence } 2015\end{array}$ & $\begin{array}{l}\text { Men Standardized } \\
\text { Prevalence } 2015\end{array}$ & $\begin{array}{c}\text { Annualized Women } \\
\text { Change rate 1990-2015 }\end{array}$ & $\begin{array}{c}\text { Annualized Men } \\
\text { Change rate 1990-2015 }\end{array}$ \\
\hline Global & & $5.4(5.1-5.7)$ & $25.0(24.2-25.7)$ & $-1.7(-2.0 /-1 \cdot 4)$ & $-1.3(-1.5 /-1.2)$ \\
\hline Angola & Low-intermediate & $1.6(0.9-2.6)$ & $14.2(12.5-16.1)$ & $-0.7(-3.5 / 2 \cdot 2)$ & $0.5(-0.2 / 1.3)$ \\
\hline Brazil & Intermediate & $8.2(7.5-9.0)$ & $12.6(11.8-13.5)$ & $-3.3(-3.9 /-2.7)$ & $-3.3(-3.8 /-2.9)$ \\
\hline Cape Verde & Low-intermediate & $2.5(1.7-3.6)$ & $9.8(8.0-11.7)$ & $-0.9(-3.1 / 1.3)$ & $-0.6(-1.6 / 0.6)$ \\
\hline Equatorial Guinea & Low & $1.4(0.9-2.1)$ & $6.9(5.6-8.4)$ & $-1.0(-3.5 / 1.3)$ & $-0.6(-1.7 /-0.5)$ \\
\hline Guinea-Bissau & Low & $1.0(0.6-1.5)$ & $11.4(9.4-13.5)$ & $-0.9(-3.4 / 1.6)$ & $-0.3(-1.4 /-0.8)$ \\
\hline Mozambique & Low & $3.1(2.5-3.8)$ & $17.2(14.5-20.1)$ & $-1.5(-2.7 /-0.2)$ & $-0.5(-1.5 /-0.5)$ \\
\hline Portugal & High-intermediate & $12.7(11.0-14.8)$ & $24.9(22.7-27.2)$ & $1.3(0.4 / 2.1)$ & $-1.0(-1.4 /-0.6)$ \\
\hline São Tomé and Principe & Low-intermediate & $1.0(0.7-1.5)$ & $6.2(5.0-7 \cdot 3)$ & $-1.0(-3.2 / 1.3)$ & $-0.2(-1.3 / 0.9)$ \\
\hline East Timor & Low-intermediate & $12.4(9.8-15.1)$ & $39.8(37.2-42.5)$ & $4.5(2.8-6.3)$ & $-0.1(-0.5 / 0.4)$ \\
\hline
\end{tabular}

SDI: sociodemographic index. The SDI is the weighted geometric mean of the per capita income, educational level, and total fertility rate. ${ }^{3}$

These measures stemmed from adherence to the recommendations by the World Health Organization's Framework Convention on Tobacco Control (FCTC), ${ }^{9}$ such as banning of terms such as ultra-light, light, low tar, and mild or any other terms implying that cigarettes are not so harmful. The PSCs have joined the FCTC at different moments, as discussed below in the section "Legislation."

The percentage of deaths attributed to tobacco use across 195 countries increased from 7.28 (7.01-7.56) million in 2007 to $8.10(7.79-8.42)$ million in 2017 , an increase of $11.3 \%$ (9.1-13.4\%), according to the Global Burden of Disease (GBD) study. ${ }^{1}$ The same occurred with the DALYs, from 199.80 (188.0-211.72) million in 2007 to 213.39 (201.16-226.67) million in 2017, a $6.8 \%$ increase (4.6-9.0\%). A similar trend was observed in regard to ischemic heart diseases, from 1.76 (1.68-1.83) million deaths in 2007 to 1.93 (1.83-2.02) million deaths in 2017 , a $7.8 \%$ increase (4.6-11.1\%), whereas the DALYs increased from 44.30 (42.42-46.19) million in 2007 to 47.38 (45.12-49.71) million in 2017, a $5.6 \%$ increase (2.4-9.0\%). Similar increases were observed in relation to deaths due to ischemic stroke, from 351.19 (326.63-379.84) thousand in 2007 to 399.35 (369.15-433.38) thousand in 2017, a $13.4 \%$ (8.6-17.8\%) increase, with an increase in DALYs from 8.74 (7.96-9.54) million thousand in 2007 to 10.41 (9.42-11.50) million in 2017, a 19.3\% (14.7-23.8\%) increase. ${ }^{1}$

It is important to note that approximately $80 \%$ of the smokers reside in low- and middle-income countries, ${ }^{10}$ which represent most of the population of PSCs, where the reported decline in tobacco consumption seen in high-income countries has not been observed. ${ }^{4}$ There is already strong evidence of cost-effectiveness and opportunities to treat smoking in primary care because of its wide coverage and close and continuous physician-patient relationship. ${ }^{11}$

Considering only those risk factors valued in traditional practice, smoking is the only factor that could be completely abolished in the prevention of cardiovascular diseases (CVDs); however, broadening the spectrum and including man-made ecological and behavioral changes, there are many other factors that can be controlled.
In a social environment filled with stressful and frustrating circumstances driven by inequality, with conflicts of interest and fueled by marketing, adherence to the consumption of psychoactive substances like tobacco and alcohol is successful due to the action of these substances in the limbic system (reward circuit), leading to chemical and psychological dependence. This system is part of the evolutionary adaptation process that promoted the preservation of species and is one of the determinants of the repeated relapses observed when the patient intends to quit. ${ }^{12}$

Quitting smoking is known to be the most effective measure in the prevention of tobacco-related diseases. However, smoking does not receive the necessary attention during medical consultations, both at an outpatient and inpatient level, to initiate the process of quitting the most frequent preventable cause of CVD and many cancers. ${ }^{11}$ Thus, the objective of this article is to provide an instrument to be used by healthcare professionals in their daily practice in the fight against smoking.

\section{Epidemiology and physiopathologic mechanisms}

Table 2 shows the risk attributable to cigarette smoking for some diseases in the PSCs, presented as the percentage of deaths and the percentage of risk attributed to smoking. When smokers and never smokers are compared, the risk of smokers is 2 to 3 times higher for stroke, ischemic heart disease, and peripheral vascular disease; 23 and 13 times higher for malignancy in men and women, respectively; and 12 to 13 times higher for chronic obstructive pulmonary disease. Smokers also have a 2.87 increased risk of death from myocardial infarction compared with nonsmokers. ${ }^{3}$

Smoking is also associated with increased blood pressure and related complications like death and decline in renal function. The same applies to abdominal aortic aneurysms, which have an increased risk attributable to smoking, as well as increased aneurysm growth rate when smokers and nonsmokers are compared. Smoking has been associated with cardiac rhythm disorders such as increased frequency 


\section{FSCLP Statement}

Table 2 - Percentage of deaths and attributed risk of tobacco consumption in the various Portuguese-speaking countries ${ }^{3}$

\begin{tabular}{|c|c|c|c|c|c|}
\hline Year 2017 & Ischemic heart disease & Stroke & $\begin{array}{l}\text { Lung, trachea, and } \\
\text { bronchial cancer }\end{array}$ & $\begin{array}{l}\text { Chronic obstructive } \\
\text { pulmonarydiseases }\end{array}$ & $\begin{array}{l}\text { Alzheimer's disease } \\
\text { and other dementias }\end{array}$ \\
\hline & $\begin{array}{c}\text { DEATH ATTRIBUTED } \\
\text { RISK Tobacco Use } \\
\%(95 \% \mathrm{CI})\end{array}$ & $\begin{array}{c}\text { DEATH ATTRIBUTED } \\
\text { RISK Tobacco Use } \\
\%(95 \% \mathrm{CI})\end{array}$ & $\begin{array}{c}\text { DEATH ATTRIBUTED } \\
\text { RISK Tobacco Use } \\
\%(95 \% \mathrm{CI})\end{array}$ & $\begin{array}{c}\text { DEATH ATTRIBUTED } \\
\text { RISK Tobacco Use } \\
\%(95 \% \mathrm{Cl})\end{array}$ & $\begin{array}{c}\text { DEATH ATTRIBUTED } \\
\text { RISK Tobacco Use } \\
\%(95 \% \mathrm{Cl})\end{array}$ \\
\hline \multirow{2}{*}{ Angola } & $4.79(4.06-5.60)$ & $3.99(3.43-4.59)$ & $0.62(0.50-0.74)$ & $1.24(1.01-1.67)$ & $0.90(0.78-1.03)$ \\
\hline & $22.51(19.74-25.50)$ & $42.00(13.13-17.78)$ & $56.32(51.09-61.04)$ & $32.93(26.55-38.62)$ & $13.26(8.21-18.66)$ \\
\hline \multirow{2}{*}{ Brazil } & $13.03(12.7-13.27)$ & $9.10(8.88-9.29)$ & $2.40(2.35-2.46)$ & $4.83(4.71-4.96)$ & $5.44(5.37-5.50)$ \\
\hline & $24.41(22.31-26.56)$ & 16.60 (14.77-18.51) & $64.01(61.19-66.66)$ & $46.63(41.89-51.37)$ & $13.29(7.94-19.28)$ \\
\hline \multirow{2}{*}{ Cape Verde } & $15.39(14.47-16.41)$ & $7.28(6.43-8.07)$ & $1.65(1.51-1.79)$ & $2.11(1.85-2.63)$ & $5.49(5.16-5.81)$ \\
\hline & 8.78 (7.34-10.32) & $7.35(5.99-8.71)$ & $32.99(28.26-37.79)$ & $19.03(14.88-22.74)$ & $2.93(1.37-4.84)$ \\
\hline Equatorial Guinea & $3.80(3.24-4.40)$ & $2.95(2.52-3.40)$ & $0.65(0.46-0.84)$ & $1.30(0.96-1.89)$ & $1.35(1.12-1.60)$ \\
\hline \multirow{2}{*}{ Guinea-Bissau } & $6.22(5.36-7.04)$ & $5.59(4.87-6.31)$ & $0.44(0.33-0.55)$ & $1.30(1.07-1.53)$ & $0.90(0.75-1.14)$ \\
\hline & $11.6(9.60-13.87)$ & $8.16(6.45-10.09)$ & 32.58 (26.63-38.67) & $19.19(14.65-23.83)$ & $2.99(1.43-5.07)$ \\
\hline \multirow{2}{*}{ Mozambique } & $3.77(3.31-4.26)$ & $5.58(4.86-6.35)$ & $0.39(0.33-0.45)$ & $0.91(0.77-1.08)$ & $0.88(0.71-1.01)$ \\
\hline & $18.74(15.5-22.23)$ & $14.00(11.2616 .60)$ & 48.74 (43.34-54.23) & 32.06 (26.60-37.33) & $8.56(4.20-13.38)$ \\
\hline \multirow{2}{*}{ Portugal } & $12.1(11.53-12.70)$ & $13.91(13.31-14.53)$ & $3.87(3.61-4.11)$ & $5.11(4.81-5.42)$ & $9.49(9.07-9.86)$ \\
\hline & $12.69(11.61-13.74)$ & $7.72(6.92-8.54)$ & $64.32(61.42-66.93)$ & $31.71(27.32-36.26)$ & $7.29(4.37-10.45)$ \\
\hline \multirow{2}{*}{ São Tomé and Príncipe } & 9.77 (8.63-10.92) & $8.61(7.60-9.93)$ & $1.39(1.06-1.73)$ & $5.19(4.23-6.07)$ & $2.28(2.07-2.48)$ \\
\hline & $8.59(6.9-10.34)$ & $5.51(4.36-6.79)$ & $33.33(26.09-40.32)$ & $18.26(14.46-22.25)$ & $3.26(1.62=5.33)$ \\
\hline \multirow{2}{*}{ East Timor } & $13.00(10.30-15.20)$ & $15.26(13.18-17.24)$ & $2.03(1.65-2.68)$ & $4.34(3.59-5.08)$ & $2.66(2.22-3.07)$ \\
\hline & $24.67(20.66-28.66)$ & $17.21(14.23-20.33)$ & $59.83(53.01-66.64)$ & $47.43(38.34-54.27)$ & $12.18(6.20-18.91)$ \\
\hline
\end{tabular}

Cl: confidence interval

of atrial fibrillation and ventricular tachycardia, and with an increased risk of heart failure and related morbidity and mortality. ${ }^{13,14}$

The main tobacco-related diseases and their relative percentages (in parentheses) include coronary diseases and myocardial infarction (25\%); chronic obstructive pulmonary diseases (85\%); pulmonary neoplasms (90\%); neoplasms of the mouth, pharynx, larynx, esophagus, stomach, pancreas, kidney, bladder, cervix, breast (30\%); and cerebrovascular diseases (25\%). ${ }^{1,15}$

The risk of ischemic heart disease and related mortality increase with the smoking duration (in years) and the number of cigarettes smoked per day; the risk of disease occurs at all levels of cigarette consumption, even for individuals consuming fewer than five cigarettes per day and passive smokers. In addition, patients who stop smoking after coronary artery bypass surgery have a reduced risk of hospitalization for heart disease. Smoking cessation is the only effective treatment to prevent progression of thromboangiitis obliterans, improving symptoms and reducing the risk of amputation throughout life. ${ }^{15,16}$

Smoking cessation has several benefits that should be mentioned to smokers during consultation (Table 3). Cigarettes contain more than 7,000 toxic substances, which contribute to CVD in different ways, including adverse hemodynamic effects like increased blood pressure and heart rate, imbalance between supply and consumption of oxygen, changes in coronary blood flow, dysfunction and endothelial damage, hypercoagulability and thrombosis, chronic inflammation, and lipid abnormalities, in addition to serving as a substrate for the occurrence of arrhythmias and cardiovascular events. These effects can be observed even in passive smokers. ${ }^{13,17}$

\section{Factors associated with tobacco consumption}

Tobacco use must be considered a chronic disease that can begin in childhood and adolescence, since about $80 \%$ of the individuals who experiment tobacco do so under the age of 18 years. Also, there is a direct relationship between the onset of smoking and the maintenance of the habit in adult life. Thus, primordial prevention is an essential step in smoking control. Primordial prevention of smoking is understood as the prevention of smoking initiation among children and adolescents. Children who use tobacco for 12 months inhale the same amount of nicotine per cigarette as adults do and experience the symptoms of addiction and withdrawal, which usually develop very quickly at this age. One way to approach primordial prevention is by age groups, by observing five main items ("5 As") for each group: ask, in the sense of inquiring, questioning; advise smoking cessation; assess the motivation and symptoms of tobacco dependence; assist in the attempt to quit smoking; and arrange periodic follow-up. ${ }^{19-21}$ 
Table 3 - Benefits of smoking cessation in the short-, medium-, and long-term

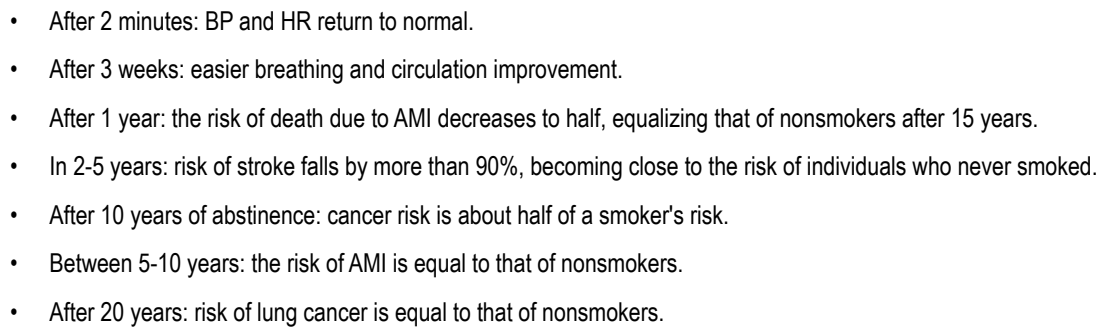

The World Health Organization has launched the MPOWER measures, with proven impact on reducing the consumption of tobacco products: ${ }^{19-21}$

Monitoring the epidemic.

Protecting the population against tobacco smoke.

Offering help to quit smoking.

Warning about the dangers of tobacco.

Enforcing the ban on advertising, promotion, and sponsorship.

Raising taxes on tobacco products.

These measures have an impact on smoking cessation at a population level, but most smokers require individualized treatment with healthcare professionals, combining a behavioral approach and often medications to quit smoking altogether.

\section{New forms of tobacco use}

New forms of smoking have emerged in the last decade and are advertised as having a reduced or absent risk, like JUUL, popular electronic cigarettes that work as vaporizers of encapsulated nicotine, flavors, and other contents in small replaceable cartridges called "pod mods." These devices, already in their third generation, associate nicotine with other vaporizing or flavoring substances with effects that are still poorly known, but have the potential of inducing health risks. ${ }^{13,14}$

As a result of well-developed marketing campaigns promoting the introduction of new forms of tobacco use, there is currently an intense discussion between the lay society and the scientific community about the inherent risk of electronic cigarettes use as a cause of CVDs and neoplasms. Although the current epidemiological evidence is not extensive and the risk of these new forms of smoking appear to be lower than those of the classic form of smoking, enough evidence is available to claim that their acute consumption causes endothelial dysfunction, DNA damage, oxidative stress, and temporary heart rate increase. As for their chronic use, it seems to increase the risk of myocardial infarction, stroke, and neoplasms of the oral cavity and esophagus. ${ }^{3,13}$

Based on the apparent lower risk of use of the new forms of smoking, electronic cigarettes have been promoted as a method to quit smoking, which lacks proof. In $60 \%$ of the cases, smokers use both the classic form of smoking and electronic cigarettes, maintaining the existing high risk.
In many cases, these new forms of smoking are adopted for a short time, at which point the smoker resumes his previous habit altogether. ${ }^{13,14}$

Additionally, electronic cigarettes are considered to be a concern by the scientific community, since they lead youths to nicotine addiction and become a gateway to classic smoking.

At the present time, even though we acknowledge that the available scientific evidence is not robust, we recommend any form of smoking to be discontinued or not initiated, including oral tobacco (chewing tobacco, snus, snuff, soluble tobacco, vaping/JUUL), cigarettes, cigars, cigarillos, pipes, or narghile. Secondhand smoke should also be fought, as it exposes to the same risks of smoking, increasing them by $20-30 \% .^{13,14}$

\section{Approach to smokers}

Most smokers have the perception and recognize that tobacco is harmful to their health. However, this is not enough for them to give up smoking. Similarly, physicians recognize the harmful effects of smoking but in daily practice tend to prioritize disease treatment instead of prevention. The initial approach to a smoker is to encourage him to start treatment regardless of the type of clinical condition and the stage of his illness. Benefits of quitting smoking must be emphasized to all patients at every appointment with a healthcare professional. As many countries have restrictions on smoking in public settings, it is important to ask systematically about tobacco exposure to nonsmokers who live or cohabit with smokers, especially children and youths who may consider the habit of smoking as normal and not harmful to their health and, as in the case of individuals with asthma, may present acute worsening when exposed to tobacco (Table 4, 5, and 6). Table 7 describes common measures to monitor smoking cessation.

\section{Treatment}

Most patients require cognitive-behavioral therapy (CBT) (Table 8) backed by pharmacological support to cope with the withdrawal syndrome, which typically lasts between 2 and 4 weeks.

\section{Nicotine withdrawal syndrome}

The main signs and symptoms of withdrawal syndrome are shown in Table 9. 


\section{FSCLP Statement}

\section{Table 4 - Initial assessment in the approach to smoking}

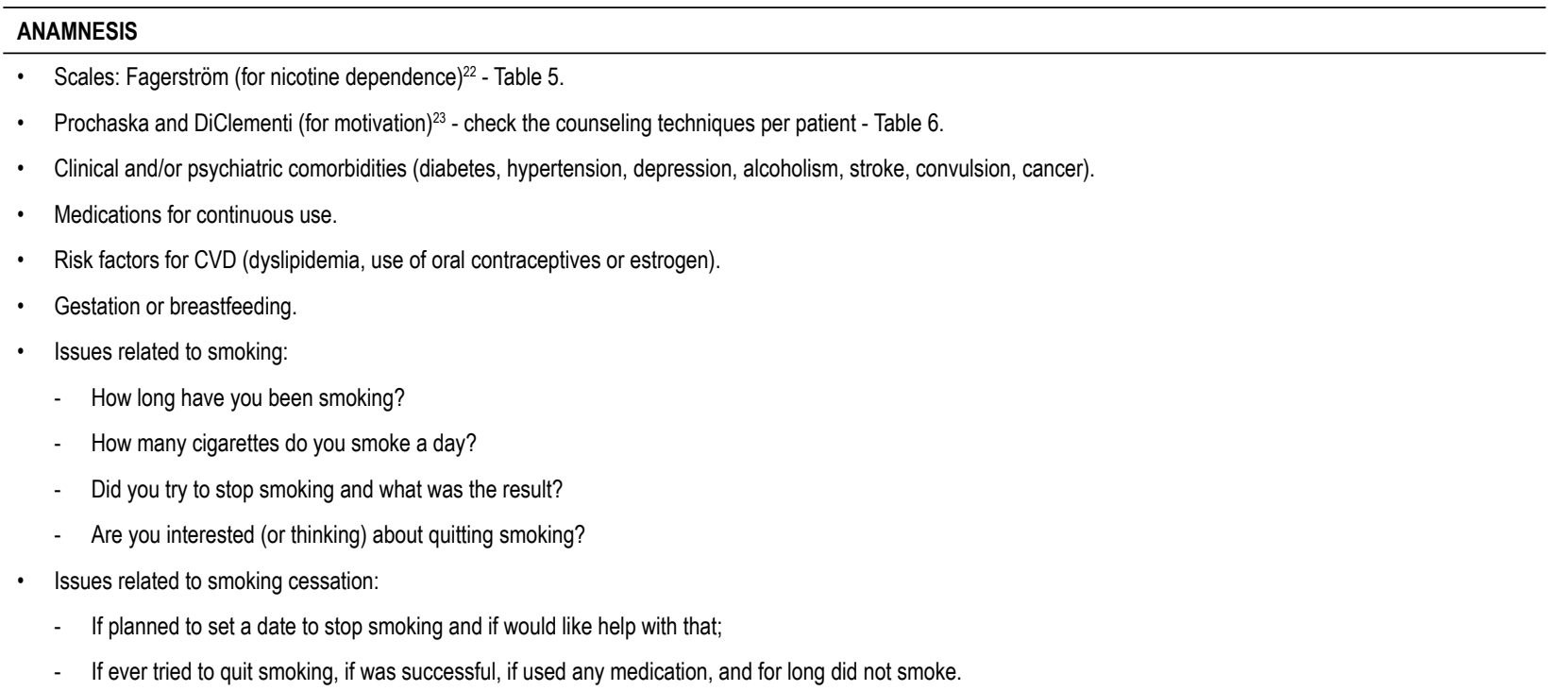

PHYSICAL EXAM

- Monitor BP, especially if using bupropion.

- Monitor body weight: weight gain may be a barrier to starting smoking cessation and a predictor of relapse.

COMPLEMENTARY TESTS

- Cell blood count, liver function tests, and serum glucose, lipids and electrolytes.

- Chest x-ray

- Electrocardiogram.

- Spirometry (not always readily available).

- Measurement of exhaled carbon monoxide (COex), if possible. This measure is directly related to the carboxyhemoglobin and cigarettes smoked per day. The cut-off value is $6 \mathrm{ppm}$.

CVD: cardiovascular disease.

Inhaled nicotine binds to specific neuronal receptors that lead to the release of excessive dopamine and endorphins, whose effects are perceived by the smoker as stimulating and pleasurable. With the dopamine reuptake, such effects dissipate and the receptors signal the need for a new stimulus (that is, they want more nicotine), which is perceived as an unpleasant sensation (limbic system, reward circuit). Regular smokers live daily with withdrawal; for withdrawal to occur, all is required is smoking to be interrupted for a short time. ${ }^{15}$

Craving is a typical symptom of the physical dependence of nicotine, defined as a strong desire or urge to smoke. Nicotine deprivation produces variable physical effects that last between 7 to 30 days and are more intense in the first 3 days after quitting smoking. However, the craving may persist for many months because the environmental stimuli that have been associated with smoking throughout life continue, and these associations are difficult to erase. In order to face these situations, the former smoker needs to develop skills and strategize to avoid triggering factors leading to lapse and relapse. ${ }^{15}$

Pharmacotherapy should be used to supplement CBT and alleviate withdrawal symptoms. The medications are recommended to be used for 3 months, extending to
6 months in cases with greater difficulty in smoking cessation. ${ }^{13}$ With pharmacological therapy, one person is estimated to successfully quit smoking (defined as smoking abstinence for 6 months) for each 6 to 23 people treated. ${ }^{11}$

Table 10 summarizes the criteria for the initiation of pharmacological therapy, which should always take into account the patient's comfort, safety, and preference, as well as the absence of contraindications for the use of a particular drug.

The medications are divided into two basic categories:

1. Nicotine replacement therapies (NRTs);

2. Non-nicotine replacement therapies (NNRTs).

NRTs are considered the first-line treatment approach for smokers and is indicated for patients with moderate to high dependence levels according to the Fagerström test. NRTs should not be combined with tobacco use. The patients should be instructed to stop smoking after initiating an NRT. The numbers needed to treat (NNT) for definitive cessation is 23 and for premature death is $46 .{ }^{11}$ Available NRTs are 24-hour release patches, chewing gum ( $2 \mathrm{mg}$ and $4 \mathrm{mg}$ ), and nicotine tablet ( $2 \mathrm{mg}$ and $4 \mathrm{mg}$ ). Table 11 describes the approach with NRTs for smoking cessation. ${ }^{11-15}$ 
Table 5 - Fagerström test for nicotine dependence ${ }^{22}$

1. How soon after you wake up do you smoke your first cigarette?

\begin{tabular}{lll}
\hline [3] Within 5 minutes [2] 6 to 30 minutes [1] 31 to 60 minutes & [0] After 60 minutes
\end{tabular}

2. Do you find it difficult to refrain from smoking in places where it is forbidden?

[1] Yes [0] No

3. Which cigarettes would you hate most to give up?

[1] The first one in the morning [0] Any other

4. How many cigarettes per day do you smoke?

\begin{tabular}{llll}
\hline [0] 10 or less [1] 11 to 20 & [2] 21 to 30 & [3] 31 or more
\end{tabular}

5. Do you smoke more frequently during the first hours after waking than during the rest of the day?

[1] Yes [0] No

6. Do you smoke when you are so ill that you are in bed most of the day?

[1] Yes [0] No

$\rightarrow$ Total: [0-2] Very low; [3-4] Low; [5] Moderate; [6-7] High; [8-10] Very high.

Table 6 - Motivation stages and counseling techniques ${ }^{23}$

- Pre-contemplative: not yet worried; not ready for behavioral change $\rightarrow$ inform the risks of continuing smoking and encourage the patient to think $\downarrow$

- Contemplative: recognizes the need for and wants to change, but still wants to smoke (ambivalence) $\rightarrow$ ponder about the pros and cons of cessation and keep yourself available to talk $\downarrow$

- Determined: wants to quit smoking and is ready to take the necessary steps $\rightarrow$ choose a date to quit smoking $\downarrow$

- Action: engaged in attitudes intended to promote changes and quit $\rightarrow$ follow-up to prevent relapse and relieve withdrawal symptoms $\downarrow$

- Maintenance: maintains the behavioral change achieved and remains abstinent $\rightarrow$ reinforce the benefits of quitting smoking and identify risk situations for relapse and coping skills $\downarrow$

- Relapse: unable to maintain the abstinence achieved and returns to the smoker's behavior $\rightarrow$ offer support, review, and resume the entire process.

\section{Table 7 - Follow-up of smoking cessation}

- Set a date to stop smoking.

- Get to know the social environment of the smoker in such a way that his family, friends, and coworkers are able to help him.

- If other family members smoke, it will be important to encourage them to quit or to smoke outside their home.

- Elaborate the action plan with nonpharmacologic and pharmacologic strategies.

- Follow-up the attempts to stop smoking.

- Inform about possible abstinence syndrome and craving on smoking cessation.

- The patient, along with the physician, should choose the cessation method to be used:

- Abrupt cessation: is usually the method of choice among smokers, and the abstinence syndrome is the main obstacle.

- Gradual cessation: the smoker can continue to smoke a small number of cigarettes indefinitely and ends up returning to the previous consumption pattern.

\section{Table 8 - Cognitive-behavioral therapy}

- Explain the mechanisms of dependence and ambivalence.

- Discuss the advantages of quitting smoking and the disadvantages of continuing to do so.

- Increase the motivation of the smoker before starting the cessation program, moving from the contemplative posture to a stage of action.

- Structured sessions with booklet support discussing the main aspects of addiction, withdrawal symptoms, and obstacles to overcome.

- Four to six weekly 90-minute sessions (essation sessions) and three to four biweekly 90 -minute sessions (maintenance sessions) in the first 3 months of treatment.

- Guide patients to set a smoking cessation date between the second and third therapy sessions, regardless of the therapeutic protocol chosen.

- The maintenance phase is focused on preventing episodes of lapse or relapse. This phase lasts 12 months, with monthly follow-up (in person or by phone).

- The first 6 months after smoking cessation are considered the most critical period for lapses or relapses. 


\section{FSCLP Statement}

Table 9 - Symptoms of nicotine withdrawal syndrome

\begin{tabular}{l|l}
\hline Neurobehavioral symptoms & Physical symptoms \\
\hline Anxiety & Reduced blood pressure \\
Headache & Reduced heart rate \\
Difficult concentration & Sweating \\
Difficult memorization & Dizziness \\
Restlessness & Craving (urgency to smoke) \\
Irritability & Tremors \\
Feel of frustration or anger & Increased appetite \\
Depressed mood & Weight gain \\
Insomnia & Motor incoordination \\
\hline
\end{tabular}

Table 10 - Determinants of initiation of drug therapy

- Smokes 20 or more cigarettes per day, OR

- Smokes the first cigarette of the day up to 30 minutes after waking up and smokes at least 10 cigarettes per day, OR

- Previous attempt with cognitive-behavioral therapy alone was ineffective due to withdrawal symptoms.
In the pharmacological approach with NNRTs, bupropion and varenicline are available as first-line medications (Table 12). ${ }^{11-15}$ Clonidine and nortriptyline are second-line treatment options, due to their side effects. The NNTs for bupropion and varenicline are 18 and 10, respectively, for successful treatment, and 36 and 20, respectively, for avoiding premature death. ${ }^{11}$ Table 13 presents a summary of the usual pharmacological treatment for smoking. ${ }^{11-15}$

\section{Legislation}

Since smoking is a population phenomenon that also imposes risks for nonsmokers, pregnant women, fetuses, and children, in addition to wasting a large amount of public (financial and organizational) resources and causing dependence (which is equivalent to making individuals vulnerable to addiction to other drugs), medical care and health education are not sufficient. Legislation must contemplate control of tobacco exploitation and use in any form, alongside the control of other addictive drugs.

Economic interests involved in tobacco growing, production, industrialization, commercialization, and advertising are large and transnational, which makes the categorization of tobacco as an issue that is purely medical

Table 11 - Nicotine replacement therapy (NRT)

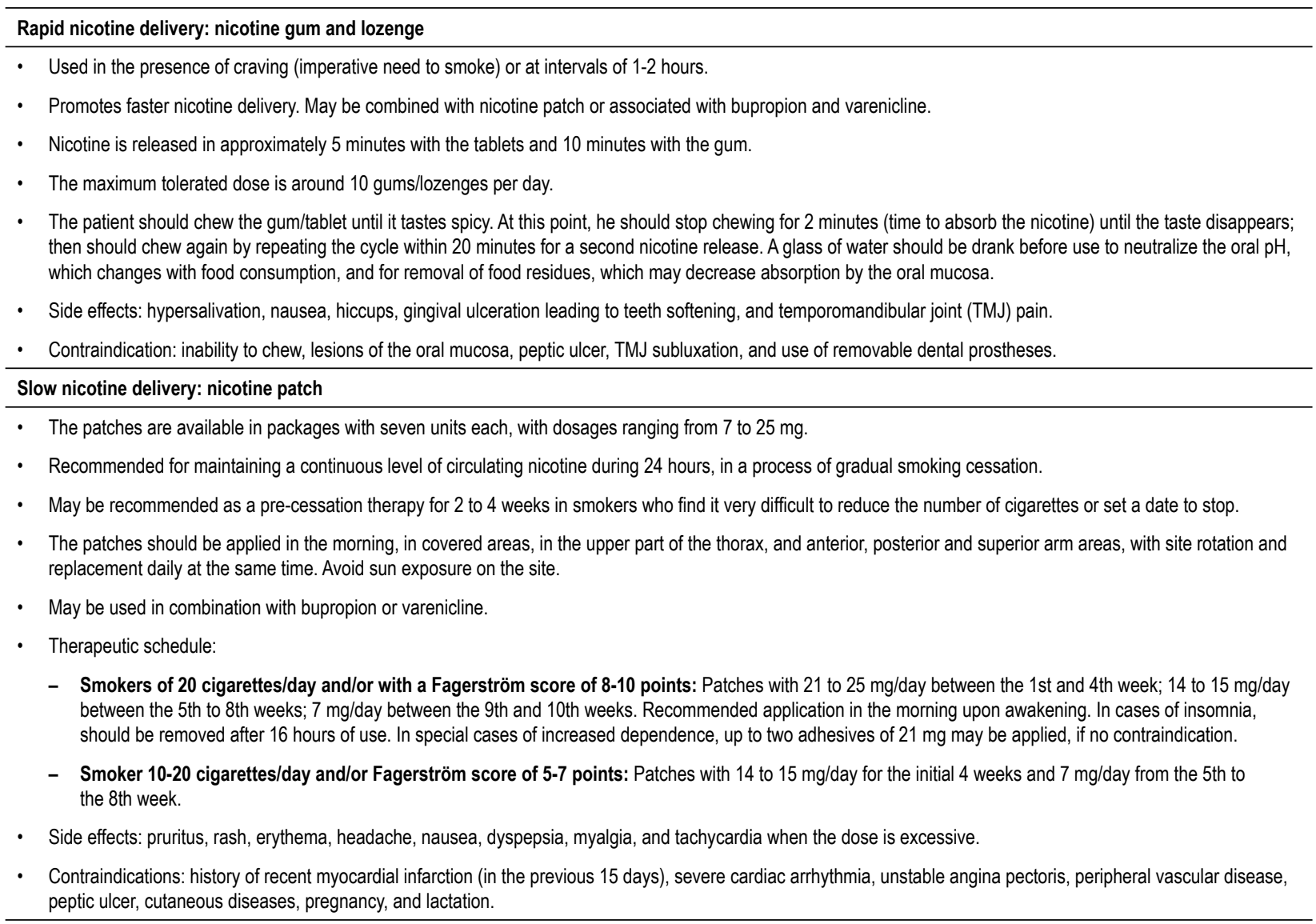


Table 12 - Non-nicotine replacement therapy (NNRT)

\section{Bupropion hydrochloride}

- Simulates some of the effects of nicotine in the brain, blocking neuronal uptake of dopamine and norepinephrine. May be used in combination with nicotine replacement therapy with patch.

- Excellent choice for subgroups of smokers who are more prone to relapse, those with depression after smoking cessation, for women, and for those with a high degree of addiction. Success cessation rates are $30 \%$ to $36 \%$.

- Therapeutic regimen: Start treatment 8 days before smoking cessation.

- $150 \mathrm{mg}$ in the morning for 3 days, followed by $150 \mathrm{mg}$ in the morning and afternoon with 8-hour intervals for 3 months; may be increased for up to 6 months. Control blood pressure; if blood pressure increases, the dose may be reduced to $150 \mathrm{mg} /$ day before discontinuation in refractory cases. Reduce doses in renal and hepatic failure to $150 \mathrm{mg} /$ day. Monoamine oxidase inhibitors should be suspended 15 days before starting bupropion. Use with caution or avoid in patients taking antipsychotics, theophylline, and systemic steroids, as it predisposes to the occurrence of seizures.

- Contraindications:

- Absolute: history of seizure (including febrile seizure), epilepsy, traumatic brain injury, electroencephalographic abnormalities, brain tumor, severe alcoholism, anorexia nervosa and bulimia, pregnancy, and lactation.

- Relative: Concomitant use of barbiturates, benzodiazepines, cimetidine, pseudoephedrine, phenytoin, oral hypoglycemic agents, or insulin.

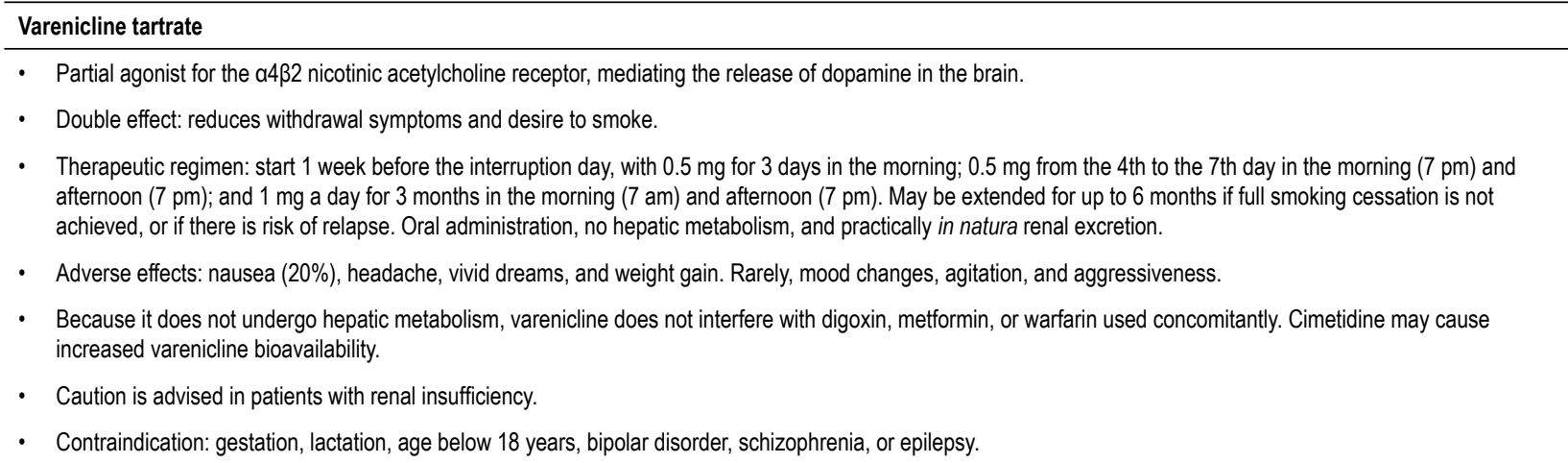

Table 13 - Usual pharmacological treatment for smoking

\begin{tabular}{|c|c|c|c|}
\hline Medication & Start of treatment & Therapeutic scheme & Duration (weeks) \\
\hline Nicotine replacement therapy: patch & On the date chosen to quit smoking & $\begin{array}{l}21-25 \mathrm{mg} / \text { day }-4 \text { weeks } \\
14-15 \mathrm{mg} / \text { day }-4 \text { weeks } \\
7 \mathrm{mg} / \text { day }-2 \text { weeks } \\
\text { Smokers with increased dependence may require } \\
\text { doses greater than } 21 \mathrm{mg}\end{array}$ & 8 to 10 \\
\hline Nicotine replacement therapy: gum or lozenge & On the date chosen to quit smoking & 2 mg or 4 mg: 1 a $4 /$ day & 8 to 10 \\
\hline Non-nicotine replacement therapy: bupropion & $\begin{array}{l}\text { One week before the date chosen to } \\
\text { quit smoking }\end{array}$ & $\begin{array}{l}\text { First to third day - } 150 \mathrm{mg} 1 \mathrm{x} \text { day } \\
\text { Fourth day to the end }-150 \mathrm{mg} 2 \mathrm{x} \text { daily }\end{array}$ & 12 \\
\hline Non-nicotine replacement therapy: varenicline & $\begin{array}{l}\text { One week before the date chosen to } \\
\text { quit smoking }\end{array}$ & $\begin{array}{l}\text { First to third day - } 0.5 \mathrm{mg} 1 \mathrm{x} \text { day } \\
\text { Fourth to seventh day - } 0.5 \mathrm{mg} 12 / 12 \text { hours } \\
\text { Eighth day to end - } 1 \mathrm{mg} 12 / 12 \text { hours }\end{array}$ & 12 \\
\hline
\end{tabular}

or limited to health services insufficient. Therefore, the World Health Organization has promoted the Framework Convention, ratified by 168 countries in $2003,{ }^{9}$ when the countries committed to observing certain principles that must be progressively incorporated into their laws. It is up to the health sectors of each country to remain vigilant and promote these principles with the population and political class.

The following are the dates of signing of the treaty and the ratifications among PSCs: Angola (June 29, 2004 / September 20, 2007), Brazil (June 16, 2003 / November 03, 2005), Cape Verde (February 17, 2004 / October 4, 2005), Equatorial Guinea (April 1st, 2004 / November 7, 2007), Guinea-Bissau
(November 7, 2008), Mozambique (June 18, 2004 / July 14, 2017), Portugal (January 9, 2004 / November 8, 2005), São Tomé and Príncipe (June 18, 2004 / April 12, 2006), and East Timor (May 25, 2004 / December 22, 2004). ${ }^{24,25}$

Organizations specifically focused on monitoring political activities and compliance with the treaty have emerged in many countries. Like the Brazilian ACT (Non-Governmental Tobacco Control Alliance - Health Promotion - http://actbr. org.br/), non-governmental organizations and national associations or committees exist within medical entities or in other healthcare segments interested in social mobilization, coordination, and permanent updating of control actions. ${ }^{24,25}$ 


\section{FSCLP Statement}

\section{Conclusions}

Smoking in all forms represents a serious public health problem in the prevention and treatment of chronic noncommunicable diseases. General practitioners and cardiologists must identify patients who smoke, become aware of all available tools, apply these tools to encourage smokers to seek professional help to quit smoking, and avoid missed key opportunities like diagnoses of coronary artery disease, peripheral arterial disease, or cerebral or tobacco-related malignancies among patients, their family members, and key society members. The increasing awareness of the population about the risks of smoking makes the current moment very favorable to approach smokers. Treatment is more accessible (NRT and bupropion are available in PSCs) and can be performed at any healthcare level.

The association of CBT with pharmacological support to cope with abstinence increases the effectiveness of the interventions. Relapses are part of the smoking dependence cycle and should serve as a lesson for a new attempt. Finally, cessation of smoking at any age brings benefits to the individual's health and to the health of those around him, and physicians must always be ready to offer care, whatever the stage in which the individual dependent on nicotine is.

New forms of smoking, especially using electronic systems, are far from proving their innocence or even contributing to the overall reduction of smoking and its harmful effects, and their use should be discouraged.

Smoking must be considered as a problem that transcends the damage caused to the organs affected by the smoke and tobacco products, and related to a set of problems produced by the individual himself involving economic, social, cultural, and ecological aspects compromising our quality of life and our own survival.

\section{References}

1. Global, regional, and national age-sex-specific mortality and life expectancy, 1950-2017: a systematic analysis for the Global Burden of Disease Study 2017 GBD 2017 Mortality Collaborators* Lancet. 2018;392(10159):1684-735

2. World Health Organization (WHO). Ambient air pollution: global exposure and burden of disease, 2016 update (in preparation). Geneva; 2016.(update in preparation). [Internet]. [Cited in 2018 Dec 10]. Available from: https:// www.who.int/nmh/publications/ncd-profiles-2018/en/

3. GBD 2015 Tobacco Collaborators. Smoking prevalence and attributable disease burden in 195 countries and territories, 1990-2015: a systematic analysis from the Global Burden of Disease Study 2015. Lancet. 2017;389(10082):885-1906.

4. Nascimento BR, Brant LCC, Oliveira GMM, Malachias MVB, Reis GMA, Teixeira RA, et al. Cardiovascular Disease Epidemiology in PortugueseSpeaking Countries: data from the Global Burden of Disease, 1990 to 2016. Arq Bras Cardiol. 2018;110(6):500-11.

5. Portugal. Ministerio da Saúde. Instituto Nacional de Saúde Doutor Ricardo Jorge, IP. Caraterísticas sociodemográficas dos fumadores diários em Portugal Continental. Análise comparativa dos Inquéritos Nacionais de Saúde/ Leite A, Machado A, Pinto S, Dias CM. Lisboa:INSA;2017.

6. Araújo C, Silva-Matos C, Damasceno A, Gouveia ML, Azevedo A, Lunet N. Manufactured and hand-rolled cigarettes and smokeless tobacco consumption in Mozambique: Regional differences at early stages of the tobacco epidemic. Drug and Alcohol Depend. 2011; 119(3):e58-e65.

7. Padrão P, Damasceno A, Silva-Matos C, Carreira H, Lunet, N. Tobacco Consumption in Mozambique: Use of distinct types of tobacco across urban and rural settings. Nicotine Tob Res. 2013;15(1):199-205.

8. GBD 2015 Risk Factors Colaborators. Global, regional, and national comparative risk assessment of 79 behavioural, environmental and occupational, and metabolic risks or clusters of risks, 1990-2015: A systematic analysis for the Global Burden of Disease Study 2015. Lancet. 2016;388(10053):1659-724.

9. World Health Organization. WHO. [Internet]. WHO Framework Convention on Tobacco Control. 2003. [Cited in 2018 Nov 18]. Available from: http:// apps.who.int/iris/bitstream/10665/42811/1/9241591013.pdf

10. Eriksen MP, Schluger N, Mackay J, Islami F. The Tobacco Atlas. 5th ed, Atlanta(Georgia): American Cancer Society;2015.

11. Van Schayck S, Williams V, Barchilon N, Baxter M, Jawad PA, Katsaounou BJ, et al. Treating tobacco dependence: guidance for primary care on life-saving interventions. Position statement of the IPCRG O. C. P. NPJ Prim Care Respir Med. $2017 ; 27(1): 38$.

12. Oliveira GMM, MalletALR. Tabagismo. In Manual de prevenção cardiovascular / [Rocha RM, Martins WA eds.]. São Paulo: Planmark; Rio de Janeiro: SOCER] - Sociedade de Cardiologia do Estado do Rio de Janeiro; 2017. p:49-60.
13. Barua RS, Rigotti NA, Benowitz NL, Cummings KM, Jazayeri M-A, Morris PB, et al. 2018 ACC Expert Consensus Decision Pathway on Tobacco Cessation Treatment. J Am Coll Cardiol.2018;72(2):3332-65.

14. Kalkhoran S, Benowitz NL, Nancy A. Rigotti NA. Prevention and Treatment of Tobacco Use. JACC Health Promotion Series. J Am Coll Cardiol. 2018;72(9):1030-45.

15. European Network for Smoking and Tobacco Prevention aisbl. (ENSP). Information release 2. SILNE- Tacking socio-economic inequalities in smoking: learning from natural experiments by time trend analysis and cross- national comparisons. Amsterdam (the Netherlands): Department of Public Health, Academic Medical Centre; 2016.

16. World Health Organization. WHO. [Internet]. Tobacco. Factsheet 339, updated June 2016. [Cited in 2017 Feb 18]. Available from: http://www. who.int/mediacentre/factsheets/fs339/en

17. National Center for Chronic Disease Prevention and Health Promotion (US) Office on Smoking and Health. The Health Consequences of Smoking — 50 Years of Progress: A Report of the Surgeon General. Atlanta, GA: Centers for Disease Control and Prevention, 2014:17.

18. McEwen A, McRobbie H, West R, Hajek P. Manual for Smoking Cessation: a guide for counsellors and practitioners. Oxford: Blackwell;2006.

19. Simão AF, Precoma DB, Andrade JP, Correa FH, Saraiva JF, Oliveira GMM, et al; Sociedade Brasileira de Cardiologia. I Diretriz brasileira para prevenção cardiovascular. Arq Bras Cardiol. 2013;101(6 supl 2):1-63 Erratum in: Arq Bras Cardiol. 2014;102(4):415.

20. World Health Organization. (WHO). MPOWER: a policy package to reverse the tobacco epidemic. Geneva, Switzerland:2008.

21. World Health Organization. (WHO). Toolkit for delivering the $5 A^{\prime}$ s and $5 R^{\prime} s$ brief tobacco interventions in primary care. Geneva: WHO Press; 2014.

22. Fagerström KO, Schneider NG. Measuring nicotine dependence: a review of the Fagerström Tolerance Questionnaire. J Behav Med.1989;12(2):159- 82 .

23. Prochaska JD, Di Clemente CC, Norcross JC. In search how people change: applications to addictive behavior. Am Psychol.1992;47(9):1102-14.

24. World Health Organization. WHO report on the global tobacco epidemic, 2013. [Cited in 2018 Nov 18]. Available from http://www.who.int/tobacco/ global_report/2013/en/index.html

25. World Health Federation. WHO. [Internet]. World Heart Federation code of practice on tobacco control. Genebra, 2004. [Cited in $2018 \mathrm{Nov}$ 18]. Available from http://www.world- heart-federation.org/fileadmin/ user_upload/documents/tobacco-code-practice.pdf 
